\title{
Increased Melting Heat Transfer in the Latent Heat Energy Storage from the Tube-and-Shell Model to the Combine-and-Shell Model
}

\author{
Agus Dwi Korawan, ${ }^{1,2}$ Sudjito Soeparman, ${ }^{1}$ \\ Widya Wijayanti, ${ }^{1}$ and Denny Widhiyanuriyawan ${ }^{1}$ \\ ${ }^{1}$ Mechanical Engineering, Brawijaya University, Malang, Indonesia \\ ${ }^{2}$ Mechanical Engineering, Ronggolawe College of Technology, Cepu, Indonesia \\ Correspondence should be addressed to Agus Dwi Korawan; ad_korawan@yahoo.co.id
}

Received 4 April 2017; Revised 8 August 2017; Accepted 10 August 2017; Published 17 September 2017

Academic Editor: Agostino Bruzzone

Copyright ( 2017 Agus Dwi Korawan et al. This is an open access article distributed under the Creative Commons Attribution License, which permits unrestricted use, distribution, and reproduction in any medium, provided the original work is properly cited.

\begin{abstract}
The melting of paraffin in thermal storage tube-and-shell and combine-and-shell models was conducted with the numerical research aim of decreasing the charge time through changing the shape of the tube into combining form. The results discussed are temperature contour, liquid-solid interface contour, temperature distribution, liquid fraction, and the average Nusselt number. The results show that the charge time in the tube-and-shell model is $2000 \mathrm{~s}$, while the combine-and-shell model is $1200 \mathrm{~s}$, meaning an overall decrease in charge time in the combine-and-shell model by $40 \%$ when compared to that of the tube-and-shell model.
\end{abstract}

\section{Introduction}

Latent heat energy storage system using Phase Change Material $(\mathrm{PCM})$ is of interest to researchers because of its many advantages, its high storage capacity being among them. However, the main drawback regarding the use of PCM is its low thermal conductivity, which causes a longer heat transfer from the heat source to the PCM and ultimately affects the total time to store energy. On the other hand, one important parameter of thermal storage is charge time, that is, the time required to store thermal energy to the Phase Change Material (PCM) during the melting process.

A lot of research was conducted to decrease the charge time, adding a wire matrix on the tube [1], adding fins on the vertical wall [2], adding fins to the rectangle [3], using composite heat sinks [4], using two Phase Change Materials [5], inserting heat pipes [6], adding nanoparticles to the PCM [7, 8], using encapsulated PCM [9], inserting matrix metal into the PCM [10], using two elliptical cylinders [11], and using porous media [12] being among them.

Experimental research on thermal storage of the tubeand-shell type to decrease the charge time was conducted by increasing the surface area of the hot wall; Rathod and Banerjee [13] conducted research using longitudinal fins, in which the results show a decrease in the melting time by as much as $12.5 \%$ and $24.52 \%$ at the fluid inlet temperature of $80^{\circ} \mathrm{C}$ and $85^{\circ} \mathrm{C}$. Hamdani et al. [14] conducted research using longitudinal and radial finned tubes; the results show that the use of longitudinal fins requires half the time to reach the melting temperature compared to the case of using radial fins. Castell et al. [15] conducted research using vertical fins on the outside of the tube; the results show a change in the coefficient of heat transfer when using external fins as a result of the increased heat transfer surface. Choi and Kim [16] compared the use of finned circular tube to a tube without fins and conveyed that the heat transfer from the tube to the PCM was influenced by the natural convection of the melting PCM, especially in the tube system without fins. Zhang and Faghri [17] conducted research using a finned tube on the inside and the results show that the addition of fins on the inside is an efficient way to increase the heat transfer when the heat carrier fluid has a low thermal conductivity.

2D numerical research in order to decrease the charge time has also been conducted by changing the position and 
shape of the hot wall. Like the work performed by Arasu and Mujumdar [18] in which they compared the phenomenon of phase change on a square grid with the heater being on vertical wall as opposed to it being on the horizontal wall, the results show that the melting time with a vertical wall heater was faster because there was an increase in natural convection. Kousksou et al. [19] compared the melting process in the rectangular cavity to the wavy wall at the bottom and the results show that the increase in the value of the amplitude of the bumpy surface causes an increase in the melting rate. Ebrahimi and Dadvand [20] compared the melting process in the square cavity with two pairs of heat source-sinks on a vertical wall, by comparing four types of cases which differed based on configuration; it was obtained that case II (each wall vertically mounted pair of heat sources/sinks with opposite positions) has the highest liquid fraction. Mostafavinia et al. [21] also compared four kinds of cases with different positions of two heat sources-sink pairs and the results show that case 1 (two heat sources placed in the bottom wall and two sinks in the wall above) has the highest liquid fraction.

From the research that was conducted, it can be concluded that in order to decrease the charge time in a thermal storage of the tube-and-shell type, one can achieve this through adding fins. By adding a fin, this means increasing the surface area of the hot wall, which has an impact on the increase of heat transfer from the hot wall to the PCM resulting in a reduced charge time.

The purpose of this numerical study is to decrease the charge time without increasing the surface area of the hot wall. This is achieved by changing the shape of the tube-andshell model to the combine-and-shell form. The results of this research are presented in the form of temperature contour, liquid-solid interface contour, temperature distribution, liquid fraction, and the Nusselt number.

\section{Physical Model}

The model of this numerical study is shown in Figure 1. The hot wall on the tube-and-shell model shaped tube has a surface area of $2975.4 \mathrm{~mm}^{2}$. With the hot wall in the combineand-shell model shaped tube at the top and cone at the bottom, the surface area of the tube is $822 \mathrm{~mm}^{2}$, and the surface area of the cone is $2153.8 \mathrm{~mm}^{2}$.

Experimental setup for validation is shown in Figure 2. The test module is tube-and-shell, the tube is made of copper and the shell made of acrylic. The thickness of tube is $0.5 \mathrm{~mm}$ and shell is $3 \mathrm{~mm}$. The position of the test module is vertical. 2 thermocouples were placed at the inlet and outlet of test module $\left(T_{\text {in }}, T_{\text {out }}\right) .3$ thermocouples (A, B, and $C$ ) were embedded into the paraffin to measure temperature distribution during the melting process.

\section{Computational Methodology}

Numerical research was conducted using ANSYS FLUENT software which uses a Geometry subprogram to build the model; in addition to that, a mesh subprogram was used for meshing and giving the necessary boundaries to the unit; meshing of the numerical model was generated by a fine structured mesh with element size of $1.030 \mathrm{~mm}$.

FLUENT was used for problem solving. In the solution setup using the solidification and melting model together, automatically the energy equation is activated by the system.

As a result of density, thermal conductivity and viscosity of paraffin depend on the temperature and the User Defined Functions (UDF) are used to determine the properties of paraffin, while the other properties are provided in the form of constants.

The initial condition of paraffin was at a temperature of $300 \mathrm{~K}$ where the hot wall was considered as the boundary condition being at a constant temperature of $343 \mathrm{~K}$, and the remaining portions of the walls were made adiabatic.

In the solution methods, the SIMPLE scheme is used with PRESTO being used for pressure. Momentum and energy used are first-order upwind. The underrelaxation factors in which the solution control is used are pressure $=0.3$, density $=1$, momentum $=0.7$, and energy $=1$. The Absolute Convergence criteria for the continuity are set to $10^{-3}$, and those for the energy are set to $10^{-7}$. The time step for integrating the temporal derivatives is set to $0.1 \mathrm{~s}$

During the solution run, temperatures were monitored at points A, B, and C located according to the model used and the average Nusselt number monitored on the hot wall with liquid fraction of paraffin being monitored and data stored every $10 \mathrm{s.}$

This numerical analysis uses the assumptions as follows:

(i) Paraffin density and viscosity depend on the temperature.

(ii) Paraffin thermal conductivity depends on the phase.

(iii) Liquid paraffin flow was laminar.

(iv) The liquid paraffin was Newtonian.

(v) Change in volume when melting was neglected.

(vi) Solid paraffin remains in place during the melting process.

\section{Thermophysical Properties}

The paraffin properties used in the numerical analysis are presented in Table 1.

\section{Validation of Numerical Model}

Before being used for numerical analysis, the model is tested against the dependence of the grid size. Tests were conducted on four mesh sizes at the tube-and-shell model, namely, 30840, 51185, 71282, and 91789. Result in the form of temperature distribution comparison is presented in Figure 3. An increasing number of elements from 30840 to 71282 resulted in a significant graphical difference, but the increase from 71282 into 91789 generated the same graph. With these considerations, use the 77043 elements for the tube-and-shell model and the 76825 elements for the combine-and-shell model.

There were 2 slope changes in the graph; the first occurred in the liquidus temperature and the second occurred in the 


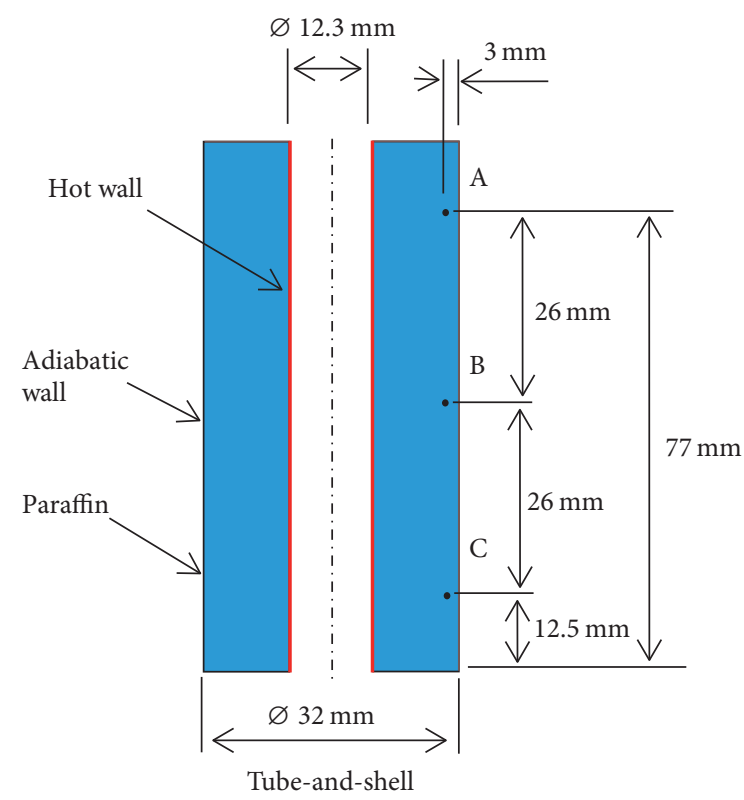

(a)

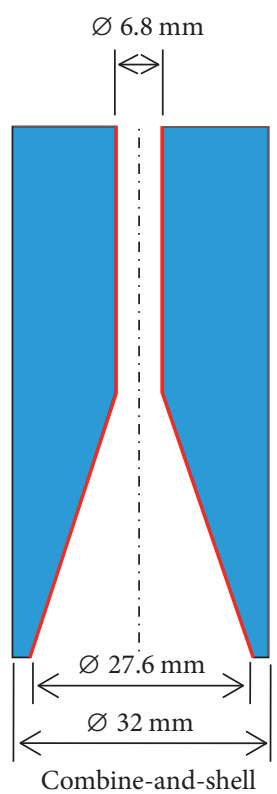

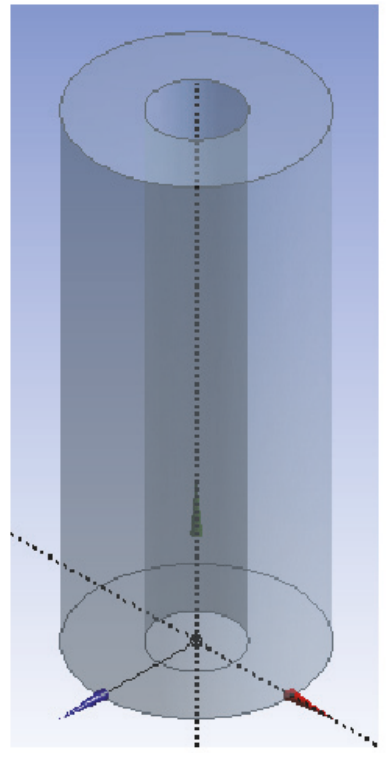

Tube-and-shell

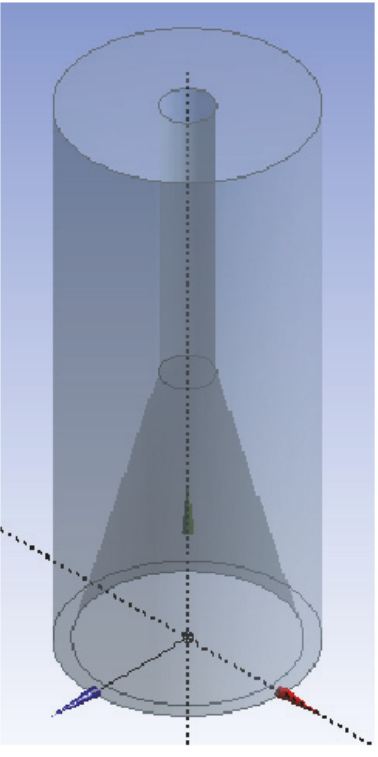

Combine-and-shell

(b)

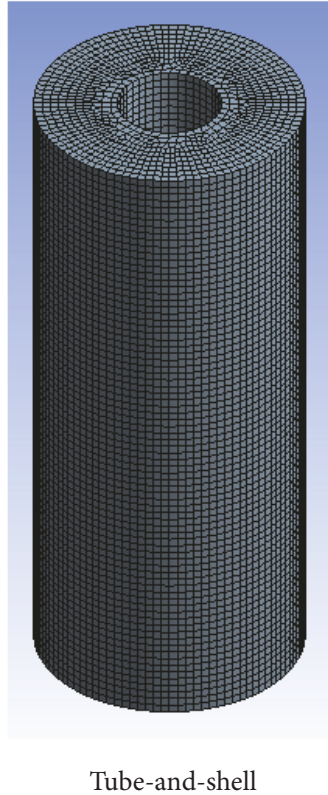

Tube-and-shell

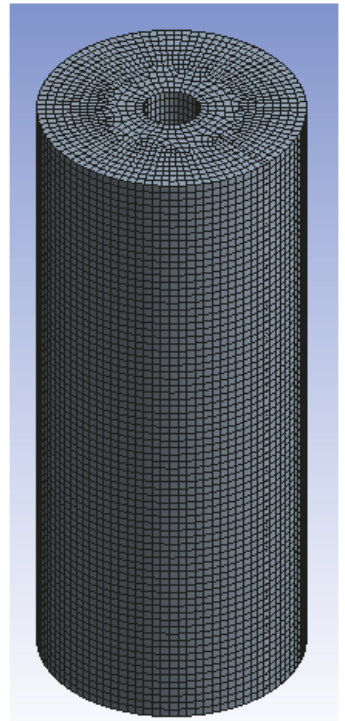

Combine-and-shell

(c)

FIGURE 1: Model for numerical analysis: (a) dimensions, (b) schematic, and (c) mesh configurations.

solidus temperature. Between these two limits is the mushy zone. The first slope change was caused by the paraffin phase change from solid to mushy and the second slope change was due to the paraffin phase change from mushy to liquid.

Validation was conducted by comparing the temperature distribution at the tube-and-shell model between the numerical approach and experimental one. The results are shown in Figure 4. At the beginning of the process it is shown that the temperature of the experimental results is greater than the numeric results; this is caused by environmental temperature at the time of the experiment being $28^{\circ} \mathrm{C}$. At the next time, the temperature of paraffin in the experimental results is lower than the numerical results; it is because to reduce the heat transfer from the shell wall towards the environment at the experimental study an insulator was used, while in the numerical study the shell is adiabatic. Temperature differences occurred between numeric study and experiment. The calculation of error in each data set yielded an average error of $9.04 \%$. A good agreement was overall between the numerical approach and experimental one. Thus, the next discussion uses the data of numerical analysis. 


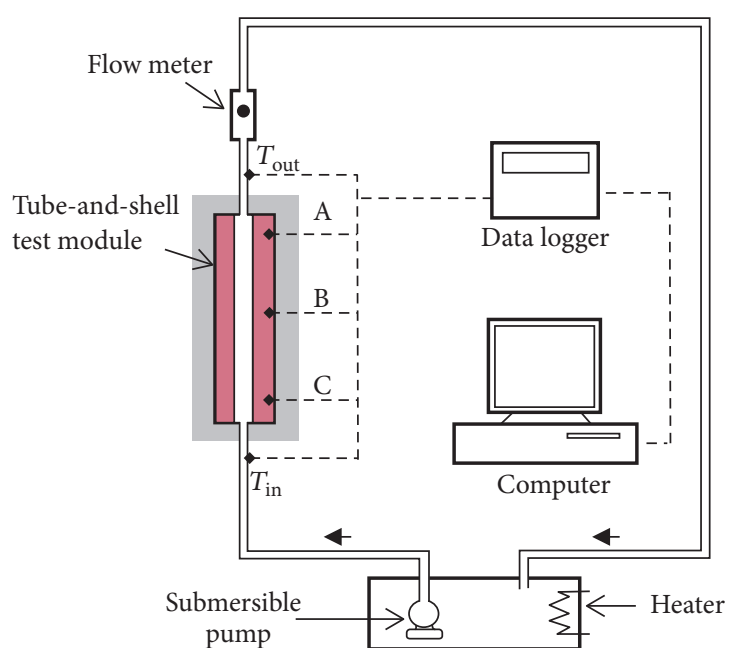

(a)
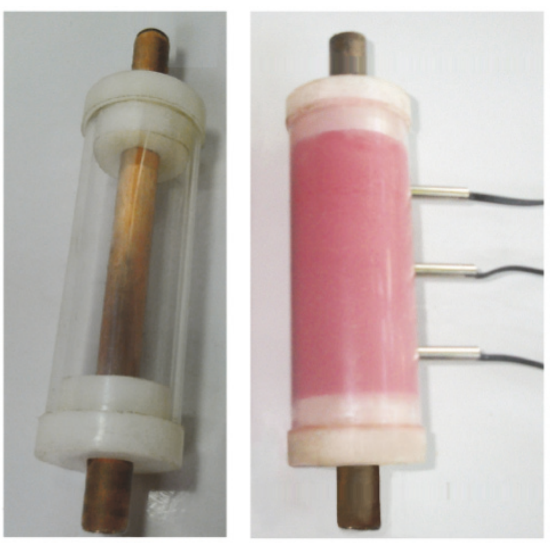

(b)

FIGURE 2: (a) Experimental setup for validation; (b) picture of tube-and-shell model.

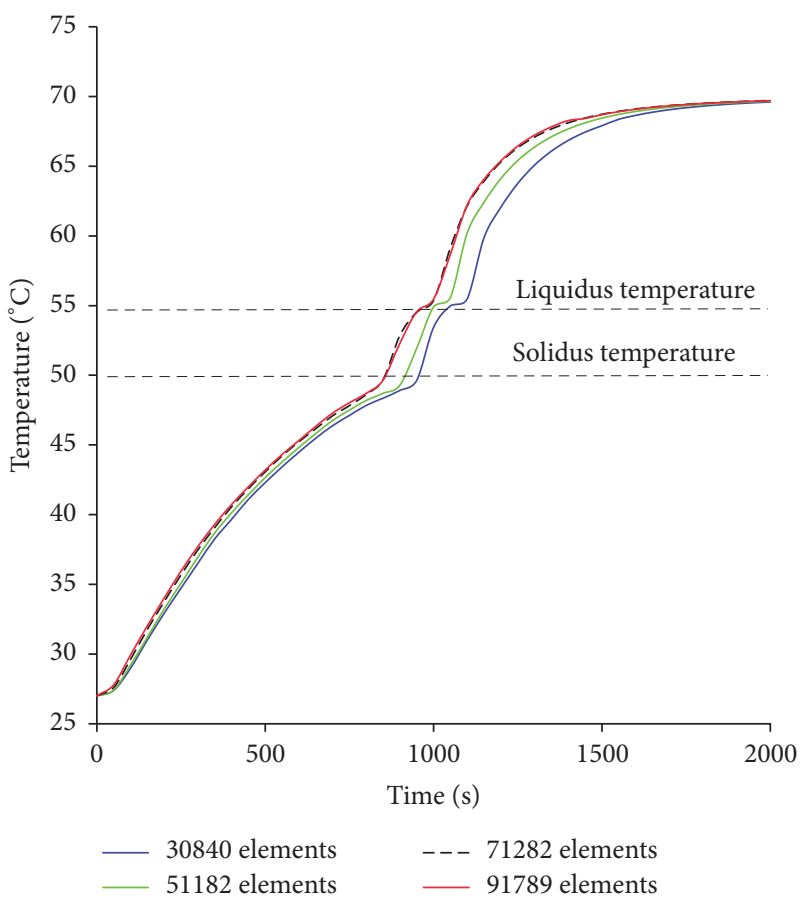

Figure 3: Temperature comparison at B on four mesh sizes.

\section{Results and Discussions}

Figure 5(a) shows the temperature contours of paraffin during the melting process in the tube-and-shell model. Conduction from the hot wall to the solid paraffin occurs at the early stage of the process (at $t=0 \mathrm{~s}$ to $t=50 \mathrm{~s}$ ), causing a temperature difference in a horizontal direction, which is evident by the temperature contour lines being parallel to the hot wall. The melting process occurs at a subsequent time, and due to the density difference of liquid paraffin it will move upwards and gather at the top region of the shell. At $t=250 \mathrm{~s}$ the

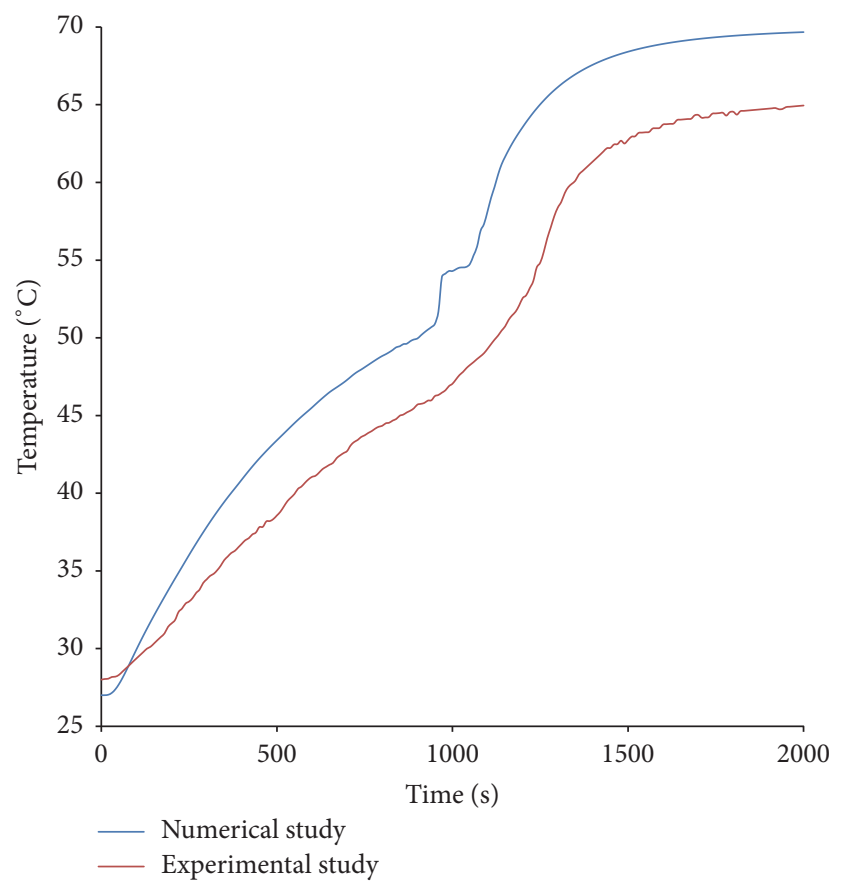

FIgURE 4: Temperature comparison at B between numerical study and experimental study.

accumulation of liquid paraffin at the top region of the shell begins to occur, which is marked by temperature contour line changes in the top region. Consecutively as time increases, the amount of liquid paraffin in the top region of the shell increases and continues to do so until all the paraffin melts.

Figure 5(b) shows the contours of liquid-solid interface at the melting process on the tube-and-shell model. At the beginning of melting process (at $t=0 \mathrm{~s}$ to $t=50 \mathrm{~s}$ ), it was dominated by conduction; it was characterized by liquidsolid interface being parallel to the hot wall. The melting 

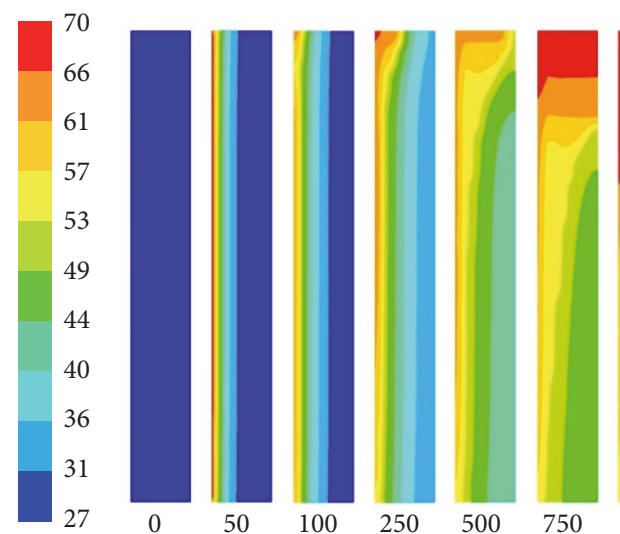

750
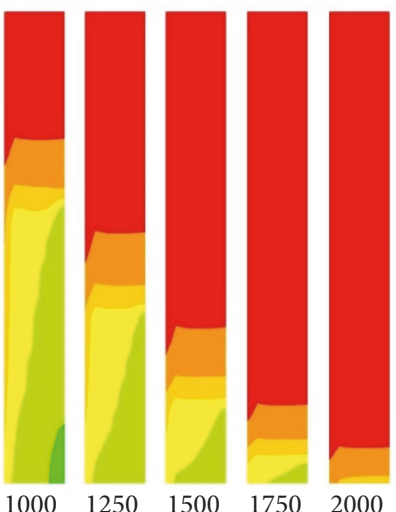

(a)
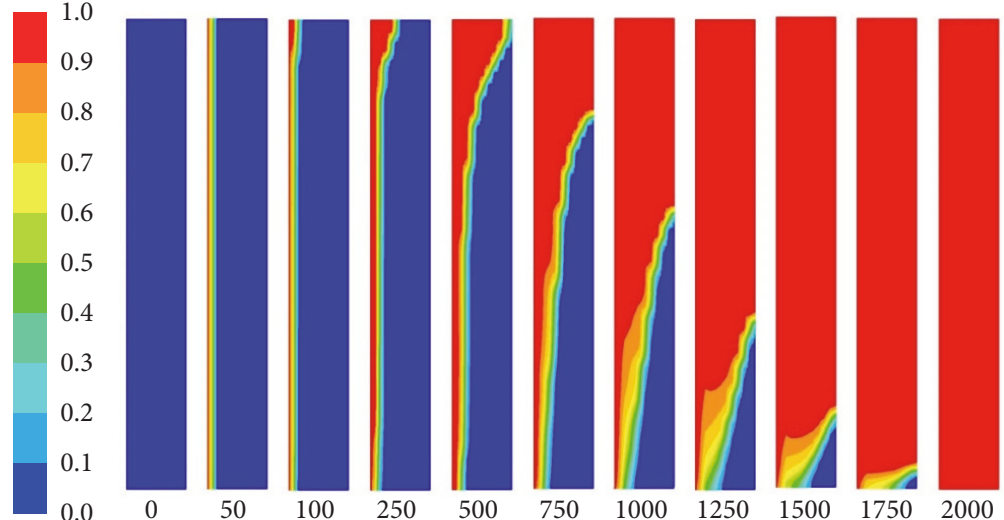

(s)

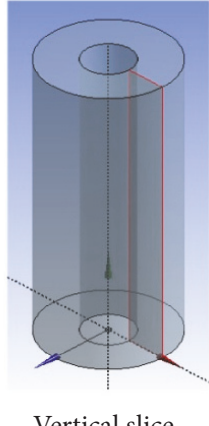

Vertical slice

(b)

FIGURE 5: (a) Contours of temperature and (b) contours of liquid-solid interface at the tube-and-shell model.

TABLE 1: The properties of paraffin.

\begin{tabular}{lcc}
\hline Property & \multicolumn{1}{c}{ Value } \\
\hline${ }^{\mathrm{a}}$ Density & $750 /(0.001(T-319.15)+1)$ & $\mathrm{kg} / \mathrm{m}^{3}$ \\
${ }^{\mathrm{b}}$ Specific heat & 3100 & $\mathrm{~J} / \mathrm{kgK}$ \\
a Solidus thermal & 0.21 & $\mathrm{~W} / \mathrm{mK}$ \\
$\begin{array}{l}\text { conductivity } \\
\text { a Liquidus thermal }\end{array}$ & $\mathrm{W} / \mathrm{mK}$ \\
conductivity & 0.12 & $\mathrm{Ns} / \mathrm{m} 2$ \\
${ }^{\mathrm{a}}$ Viscosity & $0.001 \exp (-4.25+1790 / T)$ & $\mathrm{J} / \mathrm{kg}$ \\
${ }^{\mathrm{b}}$ Latent heat & 166000 & $\mathrm{~K}$ \\
${ }^{\mathrm{b}}$ Solidus temperature & 322.7 & $\mathrm{~K}$ \\
${ }^{\mathrm{b}}$ Liquidus temperature & 327.6 & \\
\hline
\end{tabular}

${ }^{\mathrm{a}}$ Reference [18]. ${ }^{\mathrm{b}}$ Measured.

process of paraffin close to the hot wall occurs after the temperature of paraffin reaches the temperature of melting. A thin layer of liquid is formed between the hot wall and solid paraffin with the liquid paraffin near the hot wall moving upward due to difference in density. At $t=100 \mathrm{~s}$ the accumulation of liquid paraffin in the top region of the shell begins to occur. In the solid-liquid interface heat transfer of liquid paraffin to solid paraffin occurs. When the temperature of liquid paraffin decreases the density also decreases and liquid paraffin moves down. The up and down movement of liquid paraffin form the internal convection flow where heat transfer is dominated by convection. Overall, the heat transfer from the hot wall to the solid paraffin depends on two mechanisms: (1) natural convection from the hot wall to the liquid paraffin and from the liquid paraffin to the solid paraffin; (2) conduction in the solid paraffin. With continuous increase of liquid paraffin, the liquid-solid interface moves faster, and natural convection becomes greater. Liquid paraffin gathered in the top region of the shell results from higher temperatures in the top region in which the melting process occurs faster. Subsequently melting occurs in the paraffin at the lower region, and finally melting occurs in the paraffin in the bottom region of the shell until all paraffin melts at $t=2000 \mathrm{~s}$.

Figure 6(a) shows the temperature contours of paraffin during the melting process in the combine-and-shell model. Due to the surface area of hot wall in the bottom region being larger, the transfer of heat from the hot wall to the paraffin is also higher in the bottom region. At $t=50 \mathrm{~s}$ to $t=100 \mathrm{~s}$, it is evident that the temperature of the paraffin close to the cone surface is higher than the temperature of the paraffin 

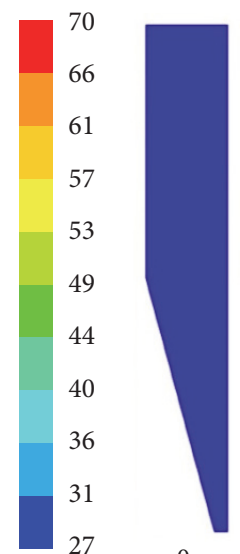

0

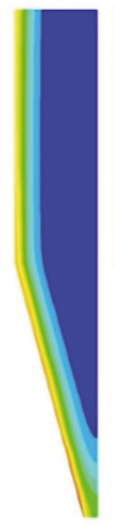

50
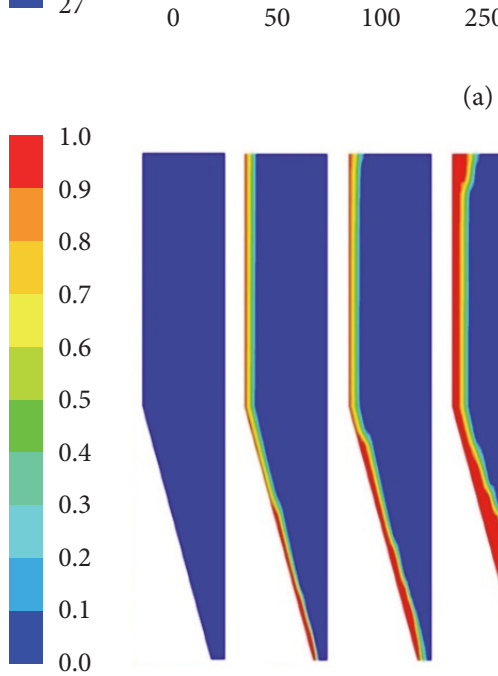

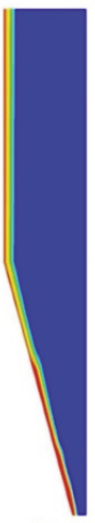

50
100

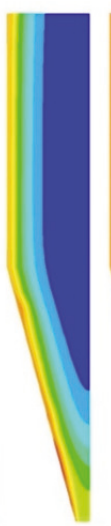

(a)

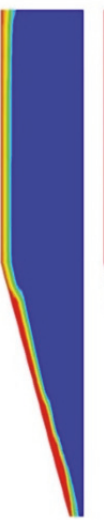

100

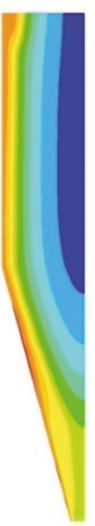

250

(s)

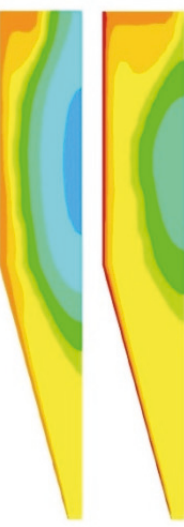

750

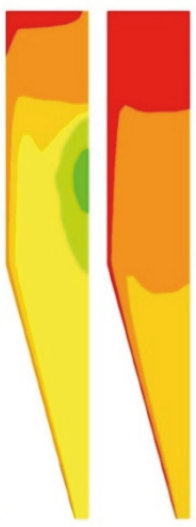

1250

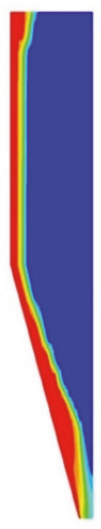

250

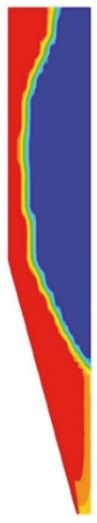

500

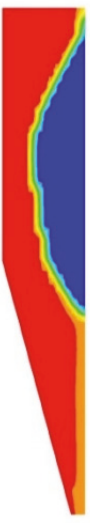

750

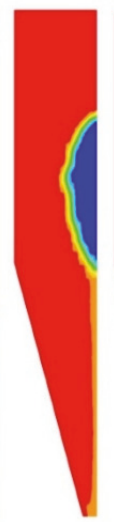

1000

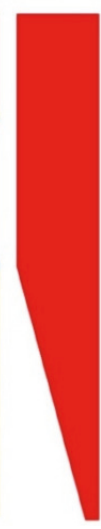

1250

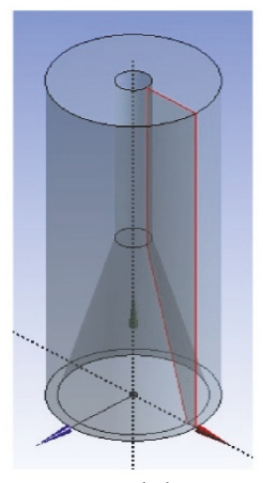

Vertical slice

(a)

$(\mathrm{s})$

Figure 6: (a) Contours of temperature and (b) contours of liquid-solid interface at the combine-and-shell model.

that is close to the tube. At the subsequent time $(t=250 \mathrm{~s})$, the accumulation of high temperature paraffin in the top region of the shell starts to occur as a result of liquid paraffin movement caused by natural convection flow. Besides an increase in temperature in the top region, there is also an increase in temperature in the bottom region though not as high as it is in the top region.

Figure 6(b) shows the solid-liquid interface contour during the melting process in the combine-and-shell model. The paraffin melting process begins at the bottom region of the shell due to the influence of the cone shape that causes faster heat transfer at the bottom region, which is observed at $t=50 \mathrm{~s}$ to $t=100 \mathrm{~s}$. Accumulation of liquid paraffin starts to occur at the top region at $t=250 \mathrm{~s}$ as a result of the flow of paraffin liquid due to a difference in density, although the melting process at the bottom region is faster, as a result of the influence of convection flow, resulting in melting in the top region also occurring quickly. This means that the melting process in the middle region of the shell is slower, evident at $t=1000 \mathrm{~s}$; solid paraffin can still be seen in the middle region of the shell. The melting process continues and finishes at $t=1250 \mathrm{~s}$.

Figure 7 shows a comparison of paraffin temperature between the tube-and-shell and combine-and-shell models. Temperature at $\mathrm{A}, \mathrm{B}$, and $\mathrm{C}$ goes up simultaneously at the beginning of the process in the tube-and-shell model. The increase in temperature is due to the distance of the three locations facing the hot wall being the same. Furthermore, the heat transfer that occurs is conduction. In addition to that, the temperature at $\mathrm{A}$ rises first then followed by temperatures $\mathrm{B}$ and $\mathrm{C}$ consecutively. At temperature of $326.7^{\circ} \mathrm{K}$ the melting occurs so that the temperature graph becomes horizontal. Melting process occurs the first time in A followed by $\mathrm{B}$ and $\mathrm{C}$, respectively. After melting is finished, the paraffin temperatures at $\mathrm{A}, \mathrm{B}$, and $\mathrm{C}$ all rise again until reaching the same temperature of the hot wall.

In the combine-and-shell model, the increase in temperature is significantly different where the temperature at $\mathrm{C}$ rises more rapidly than in the others. The increase in temperature at $\mathrm{C}$ is due to the distance being close to the hot wall. 


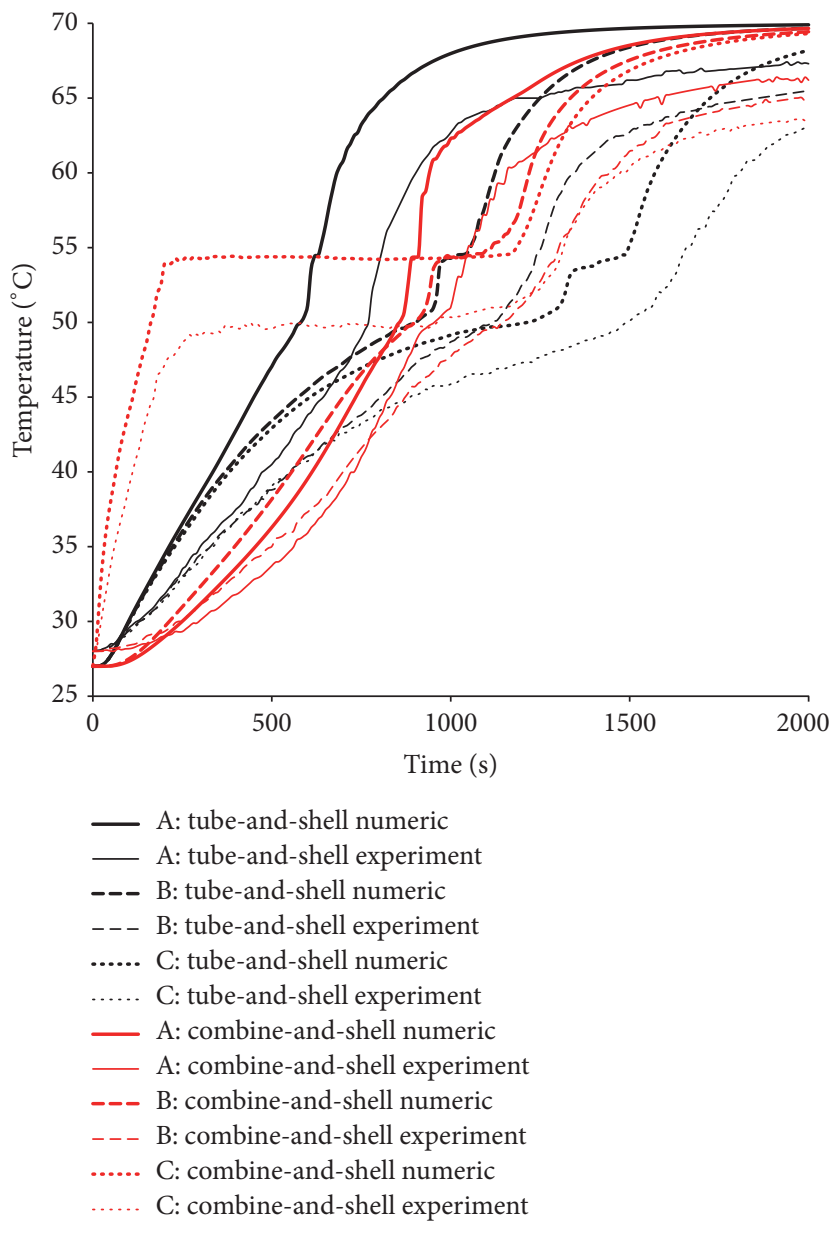

FIGURE 7: Comparison of the paraffin temperature.

Conduction heat transfer plays an important role at the beginning of the process. On the other hand, the A and B temperatures rise almost simultaneously with the temperature at $\mathrm{B}$ being slightly higher than the temperature at $\mathrm{A}$, but the melting temperature is achieved first by A; this occurs as a result of natural convection that starts to take on an important role in the subsequent process. Thus, the temperature at A rises first, followed by $\mathrm{B}$ and $\mathrm{C}$, respectively. The comparison between the numerical paraffin temperature and experiment result shows a similar trend although the experiment result was smaller.

Figure 8 shows a liquid fraction comparison between the tube-and-shell and combine-and-shell models. Liquid fraction is the ratio of the amount of liquid paraffin to the total amount (liquid + solid). If the value is equal to 0 , it means that all paraffin is solid and if a value of 1 is obtained, it means all paraffin has changed to liquid. Therefore liquid fraction is used as a parameter to determine the time of paraffin fusion in the latent heat energy storage. From the image it can be seen that the liquid fraction in the combine-and-shell model reaches a value equal to 1 earlier than the tube-and-shell model. Based on numerical data results, the time required to reach a value equal to 1 in the combine-and-shell model is $1200 \mathrm{~s}$ and $2000 \mathrm{~s}$ in the tube-and-shell model, respectively, meaning the charge time in combine-and-shell model occurs $40 \%$ faster.

The Nusselt number in Figure 9 illustrates the stages of heat transfer that occurs in both models. Heat transfer in the early stages is conduction, where the value dropped quickly. The next stage starts with the melting of the paraffin, but the liquid paraffin is still motionless; the heat transfer changes from conduction to convection (transition). Along with the increase in liquid paraffin, the liquid begins to move due to differences in density and strong convection heat transfer begins to dominate and ends with vanishing convection until entirely changing into liquid paraffin.

The occurrence of strong convection in the tube-andshell model began at $70 \mathrm{~s}$ and ended at $700 \mathrm{~s}$, with regard to the liquid-solid interface in Figure 3(b); from $700 \mathrm{~s}$ the liquid-solid interface change drastically became shorter as a result of convection and the heat transfer of liquid paraffin to solid paraffin was also reduced. This lasted until the melting process was completed at $2000 \mathrm{~s}$. Unlike the Nusselt number of the combine-and-shell model, strong convection occurs 


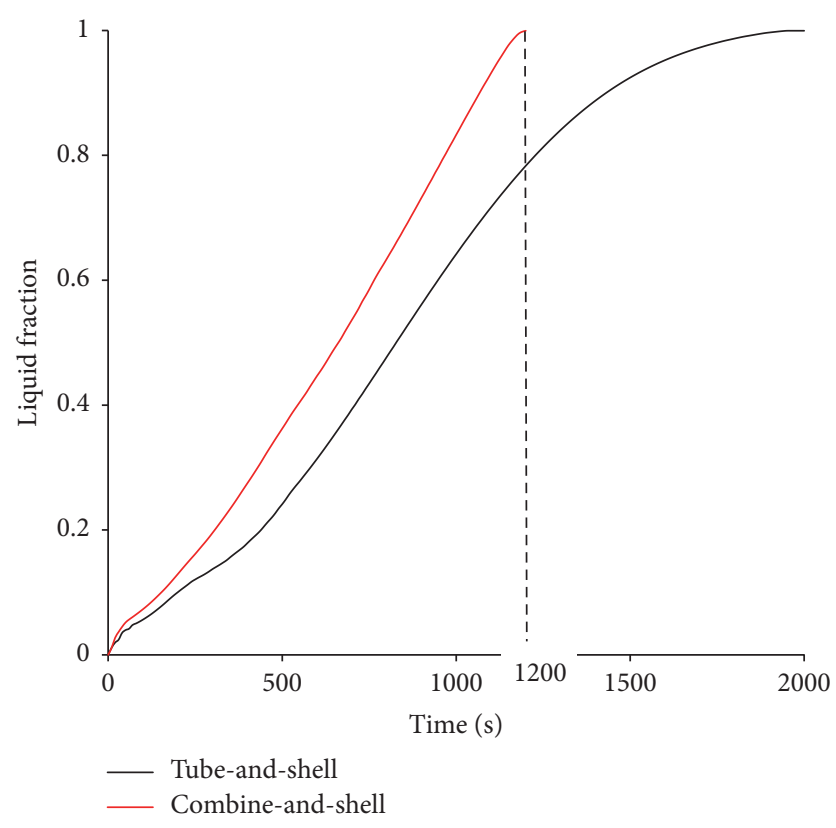

FIGURE 8: Liquid fraction comparison.

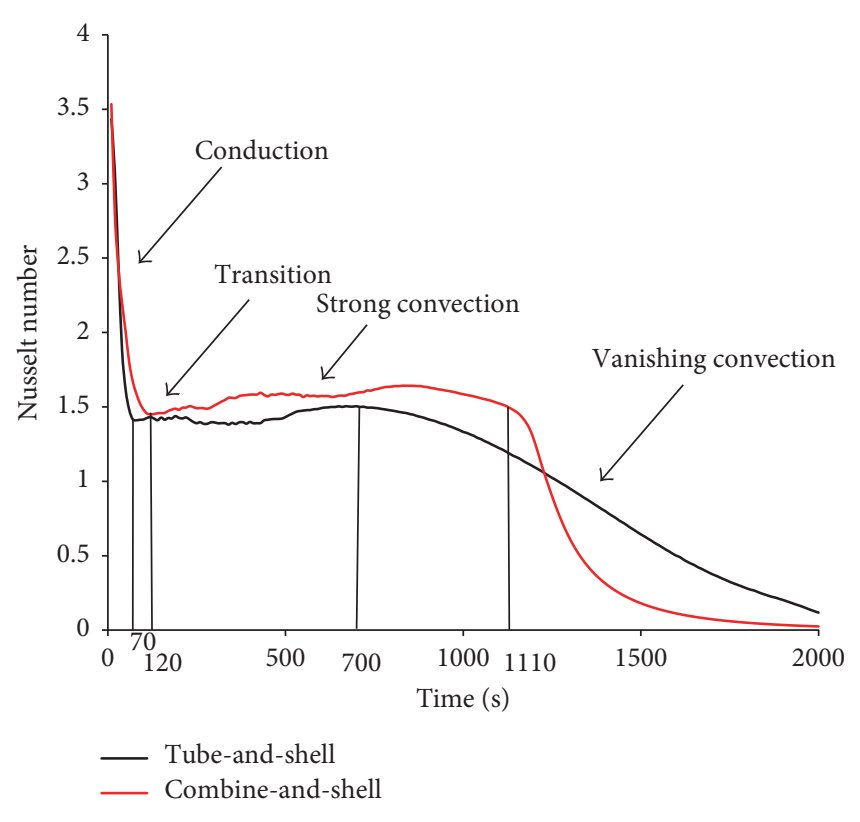

Figure 9: Average surface Nusselt number.

from $t=120 \mathrm{~s}$ to $t=1110 \mathrm{~s}$. The time span of the occurrence of strong convection in the combine-and-shell model is much longer than that of the tube-and-shell model.

\section{Conclusion}

The paraffin melting process in the thermal storage of the tube-and-shell model and the combine-and-shell model has been carried out. The results can be summarized as follows.

Temperature contour differences occurred. In the tubeand-shell model, increase in temperature in the top region of the shell was faster than the bottom region, while in the combine-and-shell model an increase in temperature occurred at the top region of the shell and the relative bottom region of the shell simultaneously.

Based on the liquid-solid interface contour, it was shown that melting in the tube-and-shell model started at the top region of the shell and ended up at the bottom region, whereas in the combine-and-shell model melting started at the top region and the bottom region of the shell and ended up at the middle region of the shell.

The distribution of temperature in both models shows a significant difference. In the tube-and-shell model, the temperature increase was uniform at the measured locations, whereas in the combine-and-shell model, overlapping temperature increases occurred.

Charge time in the tube-and-shell model took $2000 \mathrm{~s}$, while the combine-and-shell model took $1200 \mathrm{~s}$. An increase in charge time occurred in the combine-and-shell model by $40 \%$ when compared to the tube-and-shell model.

Strong convection in the combine-and-shell model occurred longer than in the tube-and-shell model.

\section{Conflicts of Interest}

The authors declare that they have no conflicts of interest.

\section{References}

[1] M. Koller, H. Walter, and M. Hameter, "Transient numerical simulation of the melting and solidification behavior of NaNo3 using awire matrix for enhancing the heat transfer," Energies, vol. 9, no. 3, article no. 205, 2016.

[2] M. Lacroix and M. Benmadda, "Numerical simulation of natural convection-dominated melting and solidification from a finned vertical wall," Numerical Heat Transfer; Part A: Applications, vol. 31, no. 1, pp. 71-86, 1997.

[3] U. Stritih, "An experimental study of enhanced heat transfer in rectangular PCM thermal storage," International Journal of Heat and Mass Transfer, vol. 47, no. 12-13, pp. 2841-2847, 2004.

[4] R. Akhilesh, A. Narasimhan, and C. Balaji, "Method to improve geometry for heat transfer enhancement in PCM composite heat sinks," International Journal of Heat and Mass Transfer, vol. 48, no. 13, pp. 2759-2770, 2005.

[5] H. A. Adine and H. El Qarnia, "Numerical analysis of the thermal behaviour of a shell-and-tube heat storage unit using phase change materials," Applied Mathematical Modelling, vol. 33, no. 4, pp. 2132-2144, 2009.

[6] J. H. Boo, S. K. Lee, and J. K. Kim, "Numerical analysis of a thermal storage system with inserted heat pipes for mediumhigh temperature range," in Proceedings of the International Heat Pipe Symposium, pp. 217-222, Taipei, Taiwan, 2011.

[7] A. Sciacovelli, F. Colella, and V. Verda, "Melting of PCM in a thermal energy storage unit: Numerical investigation and effect of nanoparticle enhancement," International Journal of Energy Research, vol. 37, no. 13, pp. 1610-1623, 2013.

[8] C. J. Ho and J. Y. Gao, "An experimental study on melting heat transfer of paraffin dispersed with $\mathrm{Al}_{2} \mathrm{O}_{3}$ nanoparticles in a vertical enclosure," International Journal of Heat and Mass Transfer, vol. 62, no. 1, pp. 2-8, 2013.

[9] H. H. Al-Kayiem and M. H. Alhamdo, "Thermal behavior of encapsulated phase change material energy storage," Journal 
of Renewable and Sustainable Energy, vol. 4, no. 1, Article ID 013112, 2012.

[10] X. Tong, J. A. Khan, and M. R. Amin, "Enhancement of heat transfer by inserting a metal matrix into a phase change material," Numerical Heat Transfer; Part A: Applications, vol. 30, no. 2, pp. 125-141, 1996.

[11] M. Faghani, M. J. Hosseini, and R. Bahrampoury, "Numerical simulation of melting between two elliptical cylinders," Alexandria Engineering Journal, 2016.

[12] Z. Liu, Y. Yao, and H. Wu, "Numerical modeling for solid-liquid phase change phenomena in porous media: shell-and-tube type latent heat thermal energy storage," Applied Energy, vol. 112, pp. 1222-1232, 2013.

[13] M. K. Rathod and J. Banerjee, "Thermal performance enhancement of shell and tube Latent Heat Storage Unit using longitudinal fins," Applied Thermal Engineering, vol. 75, pp. 1084-1092, 2015.

[14] Hamdani, Irwansyaha, and T. M. I. Mahliab, "Investigation of melting heat transfer characteristics of latent heat thermal storage unit with finned tube," in Proceedings of the 2012 International Conference on Advances Science and Contemporary Engineering, ICASCE 2012, pp. 122-128, idn, October 2012.

[15] A. Castell, C. Solé, M. Medrano, J. Roca, L. F. Cabeza, and D. García, "Natural convection heat transfer coefficients in phase change material (PCM) modules with external vertical fins," Applied Thermal Engineering, vol. 28, no. 13, pp. 1676-1686, 2008.

[16] J. C. Choi and S. D. Kim, "Heat transfer in a latent heat-storage system using $\mathrm{MgCl} 2 \cdot 6 \mathrm{H} 2 \mathrm{O}$ at the melting point," Energy, vol. 20, no. 1, pp. 13-25, 1995.

[17] Y. Zhang and A. Faghri, "Heat transfer enhancement in latent heat thermal energy storage system by using the internally finned tube," International Journal of Heat and Mass Transfer, vol. 39, no. 15, pp. 3165-3173, 1996.

[18] A. V. Arasu and A. S. Mujumdar, "Numerical study on melting of paraffin wax with $\mathrm{Al}_{2} \mathrm{O}_{3}$ in a square enclosure," International Communications in Heat and Mass Transfer, vol. 39, no. 1, pp. 8-16, 2012.

[19] T. Kousksou, M. Mahdaoui, A. Ahmed, and A. A. Msaad, "Melting over a wavy surface in a rectangular cavity heated from below," Energy, vol. 64, pp. 212-219, 2014.

[20] A. Ebrahimi and A. Dadvand, "Simulation of melting of a nanoenhanced phase change material ( $\mathrm{NePCM})$ in a square cavity with two heat source-sink pairs," Alexandria Engineering Journal, vol. 54, no. 4, pp. 1003-1017, 2015.

[21] N. Mostafavinia, S. Eghvay, and A. Hassanzadeh, "Numerical analysis of melting of nano-enhanced phase change material (NePCM) in a cavity with different positions of two heat sourcesink pairs," Indian Journal of Science and Technology, vol. 8, no. S9, p. 49, 2015. 


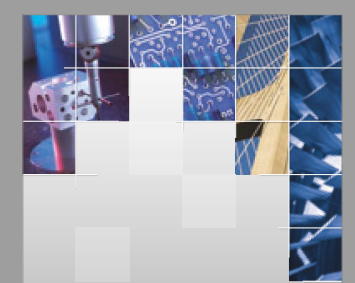

\section{Enfincering}
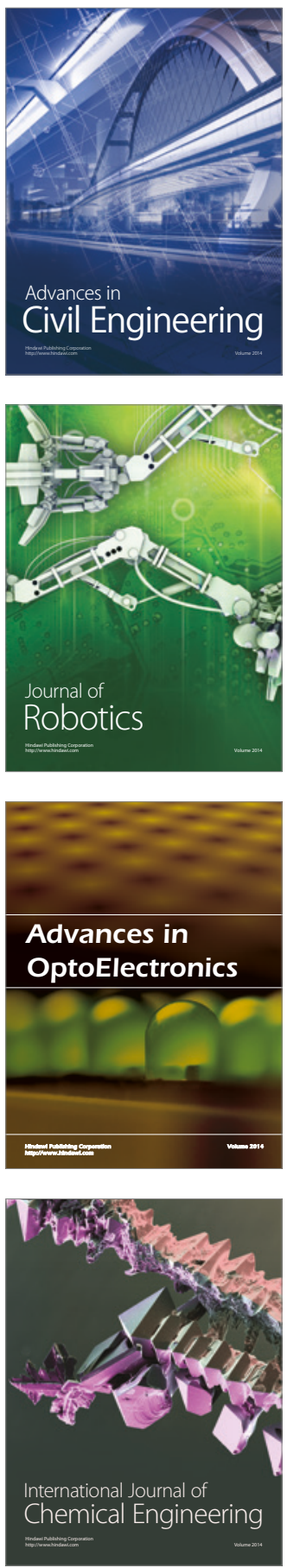

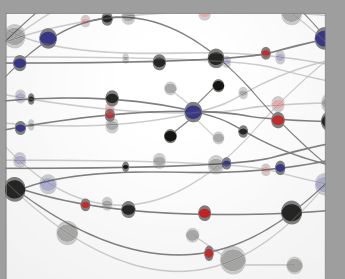

The Scientific World Journal

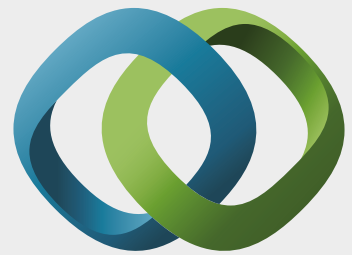

\section{Hindawi}

Submit your manuscripts at

https://www.hindawi.com
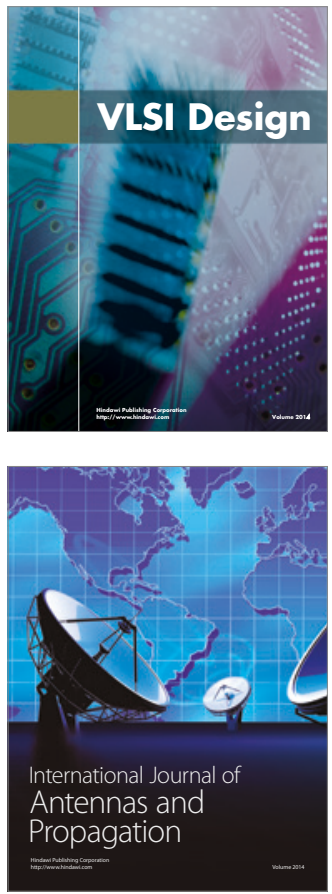

\section{Rotating}

Machinery
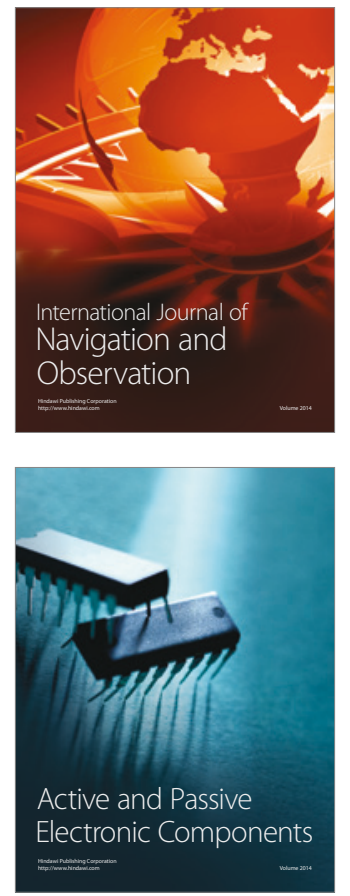
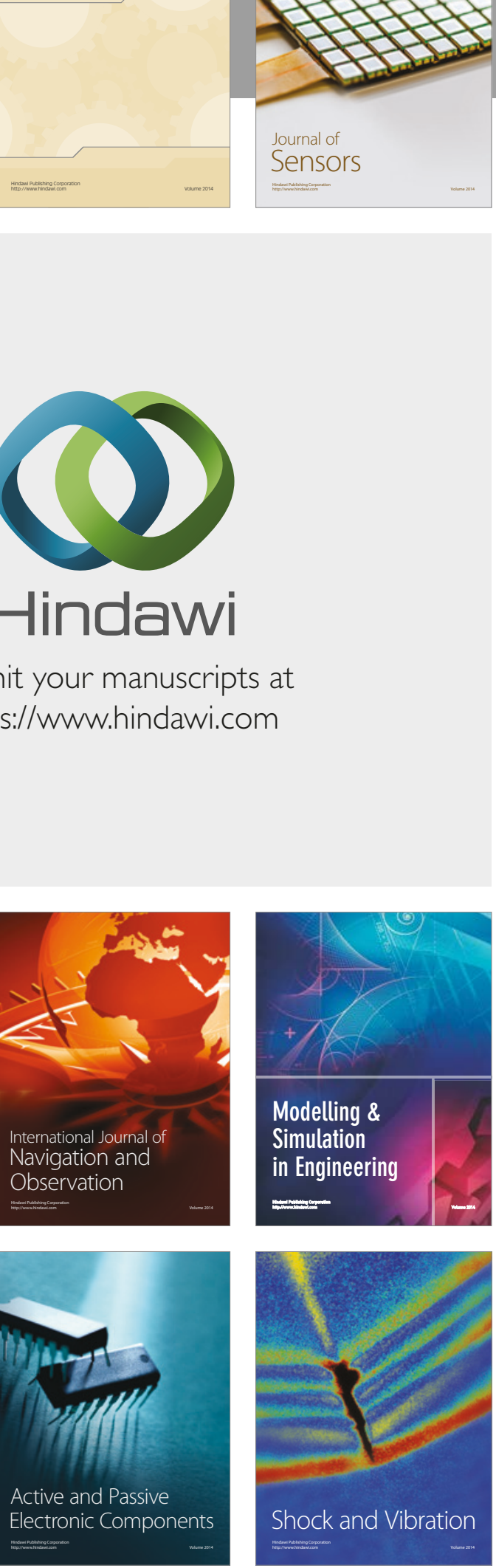
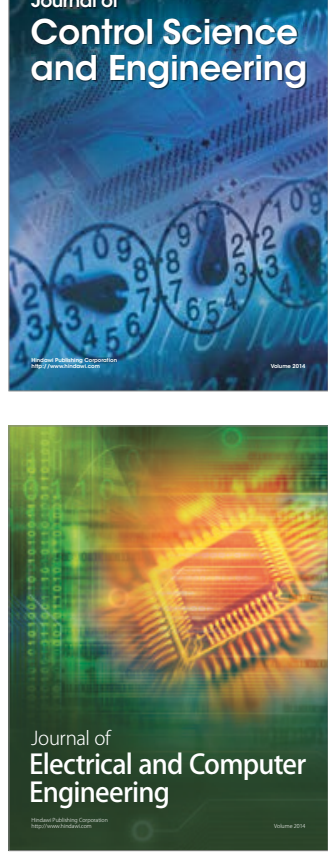

Distributed

Journal of

Control Science

and Engineering
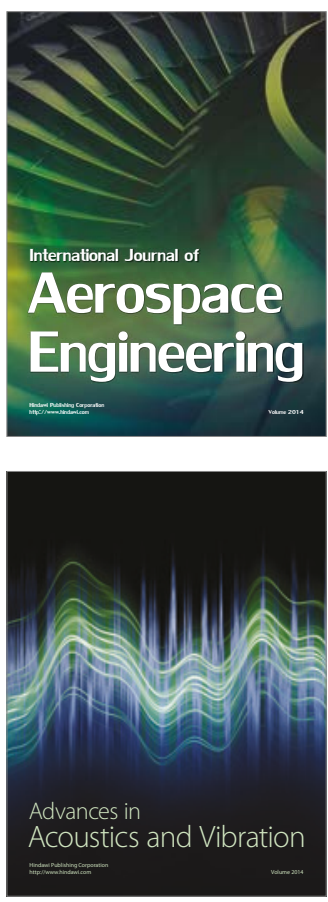

Sensor Networks 